OPEN ACCESS

Edited by:

Leonardo Freire-de-Lima

Federal University of Rio de

Janeiro, Brazil

Reviewed by:

Alana L. Welm,

The University of Utah, United States Danielle Oliveira Nascimento,

Universidade Federal Rural Do Rio De

Janeiro, Brazi

*Correspondence:

Anastasia Constantinidou constantinidou.anastasia@ucy.ac.cy

Specialty section:

This article was submitted to Molecular and Cellular Oncology,

a section of the journal

Frontiers in Oncology

Received: 06 January 2020

Accepted: 03 March 2020

Published: 18 March 2020

Citation:

Gkolfinopoulos S, Jones RL and

Constantinidou A (2020) The

Emerging Role of Platelets in the

Formation of the Micrometastatic

Niche: Current Evidence and Future Perspectives. Front. Oncol. 10:374.

doi: 10.3389/fonc.2020.00374

\section{The Emerging Role of Platelets in the Formation of the Micrometastatic Niche: Current Evidence and Future Perspectives}

\author{
Stavros Gkolfinopoulos ${ }^{1}$, Robin L. Jones ${ }^{2}$ and Anastasia Constantinidou 1,3,4* \\ ${ }^{1}$ BOC Oncology Center, Nicosia, Cyprus, ${ }^{2}$ The Royal Marsden Hospital NHS Foundation Trust and Institute of Cancer \\ Research, London, United Kingdom, ${ }^{3}$ Medical School, University of Cyprus, Nicosia, Cyprus, ${ }^{4}$ Cyprus Cancer Research \\ Institute, Nicosia, Cyprus
}

Accumulating evidence suggests that platelets play a key role in cancer metastatic dissemination through their multilevel interaction with tumor cells. Most crucial is the contribution of platelets to the formation and expansion of the early metastatic niche, a protective microenvironment that nurtures the first metastatic cells and is necessary for the establishment of overt metastatic disease. A multitude of mechanisms have been proposed toward this effect. The current review examines the implication of platelets in the three most well-studied mechanisms: (a) the initial preparation of the metastatic microenvironment by the formation of the extracellular matrix (ECM) and the recruitment of granulocytes, (b) the creation of the neovasculature (important for providing the developing tumor with oxygen and nutrients and clearing away the metabolic waste), and (c) the evasion of the immune response by the creation of an immune-suppressive environment around the developing metastases. Finally, the review provides current perspectives on the potential clinical relevance of platelets in cancer progression and their consequent role in cancer therapeutics.

Keywords: platelets, microenvironment, cancer, metastatic, niche, antiplatelet

\section{INTRODUCTION}

Derived from the megakaryocytes, platelets are small fragments of circulating cytoplasm with a key role in primary hemostasis. Increasing evidence in recent years supports their critical role in cancer progression and particularly in metastatic dissemination through their multilevel interaction with tumor cells.

The formation of the micrometastatic niche is depended upon the arrival of circulating tumor cells (CTCs) to sites distant to the primary site. Preclinical evidence now suggests that platelets have a particular role in the formation of the "early metastatic niche" $(1,2)$ based on the hypothesis that platelet-derived signals, in addition to signals derived from the tumor itself, are responsible for the recruitment of granulocytes in the early metastatic sites, where cancer cells begin to accumulate (3). The recruitment of a variety of host-derived cells, that will eventually form the tumor stroma, is mediated by the chemokines CXCL5 and CXCL7, which are secreted by the platelets that become activated after interacting with the tumor cells. Blockade of the CXCR2, which is the CXCL5/7 receptor, may result in significant reduction of metastatic spread and cancer progression (4). 
During their journey through the circulation, CTCs adhere to circulating platelets by adhesion molecules expressed on their surface, like the tissue factor and P-select in ligands (5). In this way, CTCs are engulfed in a protective shield of platelets that not only prevent their lysis from natural killer (NK) cells, but also facilitate their adhesion to the endothelium and their subsequent extravasation (6). Additionally, platelets increase their metastatic potential by triggering the TGFb- 1 and NF-kB pathways that are responsible for the epithelial-mesenchymal transition (7).

After their extravasation and the loss of their protective coating, tumor cells are in the danger of undergoing apoptosis through a process called anoikis (detachment-induced apoptosis). This results from the lack of a protective surrounding environment, and isolated cancer cells are subject to this fate, unless they manage to discover a new home in the site where they metastasize (8). This new home for the errant tumor cells is known as micrometastatic niche, and platelets, once again, constitute the major driving force for its creation (9).

The current review presents available evidence on the implication of platelets in the creation of the metastatic niche through the formation of the extracellular matrix, the building of the neovasculature and the establishment of the immune response. The future potential application of this knowledge in the clinical setting is also discussed here.

\section{THE CREATION OF THE METASTATIC NICHE}

Although the various processes leading to the creation of the metastatic niche may be overlapping, they can be divided in three major phases: the initial preparation of the metastatic microenvironment by the formation of the extracellular matrix (ECM) and the recruitment of granulocytes; the creation of the neovasculature, which is important for providing the developing tumor with oxygen and nutrients, as well as for clearing away the metabolic waste; and, lastly, the evasion of the immune response by the creation of an immune-suppressive environment around the developing metastasis (Figure 1).

\section{Preparing the Metastatic Microenvironment}

There is increasing evidence to support the idea that platelets initiate the shaping of the metastatic microenvironment in the context of early metastatic niche. This has been shown in a lung cancer murine model, where tumor-aggregated platelets have guided the creation of metastatic sites by the production of CXCL-5 and CXCL-7 cytokines that attract granulocytes (4). Furthermore, platelets may be responsible for the development of osteoblastic and osteolytic bone metastasis, as has been demonstrated in a study by Kerr et al., where tumor-induced bone formation was impaired following platelet depletion (10). Also, studies by Peyruchaud et al. have shown that tumoractivated platelets may guide bone colonization by breast cancer cells and create lytic bone metastases $(11,12)$. The proposed mechanism involves the secretion of autotaxin by activated platelets, which subsequently binds to tumor cell integrin $\alpha \nu \beta 3$, promoting the conversion of lysophosphatidylcholine (LPC) to lysophosphatidic acid (LPA). Subsequently, the autocrineacting LPA activates tumor LPA receptors, inducing the secretion of cytokines that stimulate the osteoclast-mediated bone destruction (12).

The early metastatic niche is formed mostly by ECM, by platelets and by the granulocytes that, as described above, are recruited on site by the activated platelets (13). In a study on a lung cancer model, the knockout of platelet ADP receptor (P2Y12) led to decreased lung fibronectin, which is a major component of ECM. Fibronectin is increased in the connective tissue of a pre-metastatic organ, and it is one of the most vital components of the acellular matrix of the metastatic niche. In this model, this platelet-induced downregulation of fibronectin resulted in decreased rate of metastases (14).

Conclusively, it appears that platelets can play a vital role in the very early formation of both the cellular and the acellular elements of the early metastatic microenvironment. The formation of a supportive structure consisting of ECM and hostderived cells is a prerequisite for the successful establishment of metastases.

\section{Promoting the Creation of Neovasculature}

The formation of new blood vessels from pre-existing ones in cancer is called neoangiogenesis (15). This process is particularly important for tumors sized $>2 \mathrm{~mm}$; consequently its successful completion is crucial for the development of the early metastatic site (16). Cancer growth rate is mainly influenced, and by extent, limited, by the formation of new blood vessels, which is primarily guided by platelets $(17,18)$. Indeed, platelets are the main transporters of proangiogenic factors, such as the vascular-endothelial growth factor (VEFG) (19). The pivotal role of platelets begins at the very early steps of vasculogenesis and continues until the advanced stages (20). Platelets need to be activated by tumor cells in order to fulfill this role, and this tumor cell-induced platelet activation (TCIPA) is characterized by platelet aggregation, adhesion, and an increase in both platelet numbers and platelet-derived pro-angiogenic factors (21).

The mechanisms through which platelets contribute in neoangiogenesis have been well-characterized (20). Initially, platelets become activated after coming into contact with subendothelial structures, such as collagen, in places with abnormal blood flow, such as the metastatic sites. The subsequent increase in the VEGF-induced release of von Willebrand factor causes the release of a multitude of proangiogenic factors from the activated platelets, such as VEGF, platelet-derived growth factor (PDGF), transforming growth factor, epidermal growth factor, and angiopoietin-1 (ANGPT-1) (21). The effect of this release in angiogenesis has been shown in vitro, where activated platelets are able to induce tube formation of human umbilical vein endothelial cells in matrigel tube formation assays. This has been achieved through the secretion of endothelial stimulating factors, as well as by direct cellular interactions (22). In aortic ring assays, platelets and platelet releasates induced a marked increase in angiogenesis (23).

Another hint for the importance of platelets in the process of neoangiogenesis is that platelets are activated within the tumor 


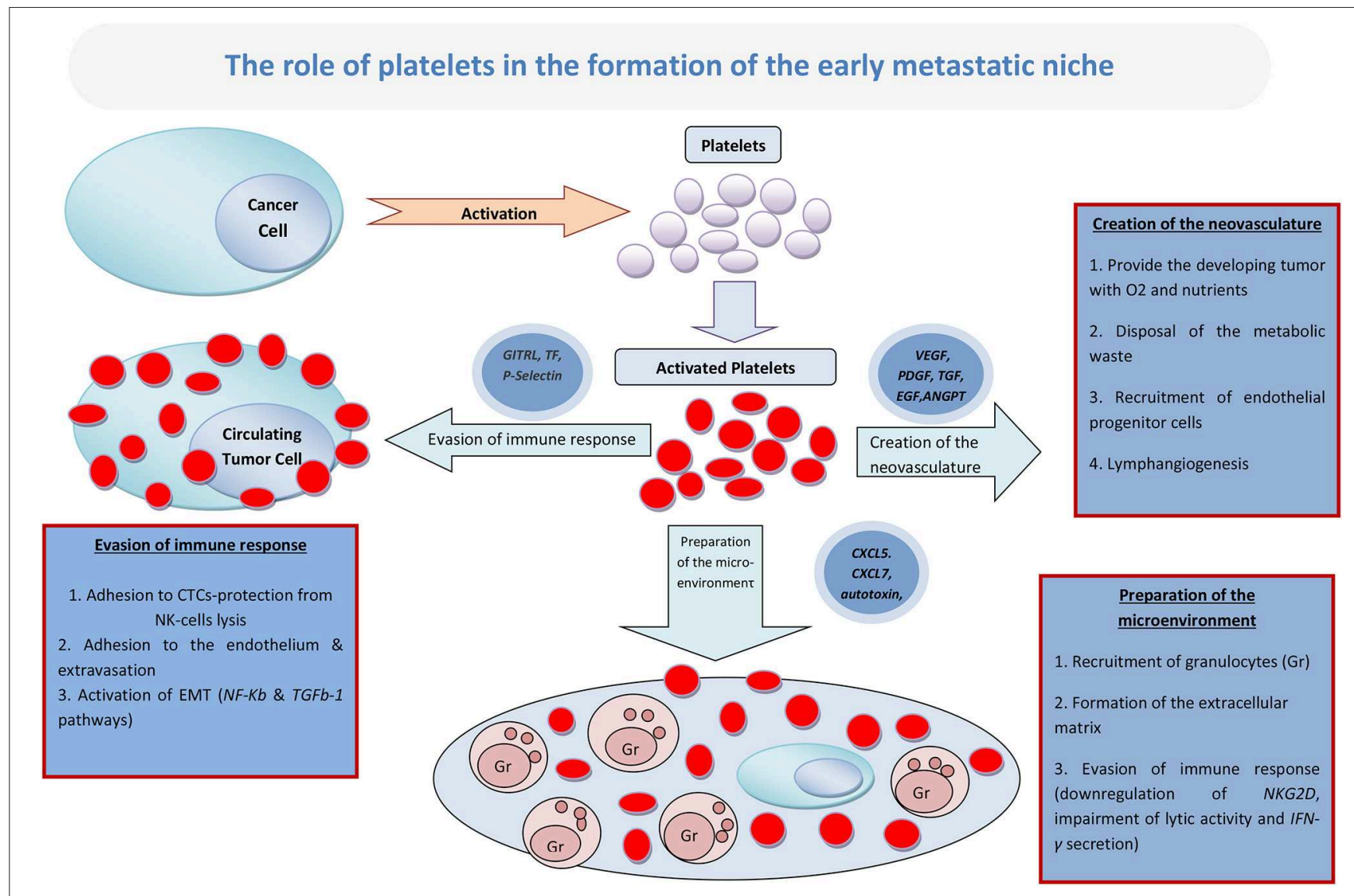

FIGURE 1 | The role of platelets in the formation of the early metastatic niche.

vasculature, subsequently secreting their VEGF-rich releasate in the tumor tissue (24-26). Also, in animal models of breast cancer and renal cell cancer, it has been demonstrated that platelets tend to adhere with increased affinity to angiogenic vessels, mediated by the upregulation of CD24 on tumor cells, thus releasing their pro-angiogenic content in the tumor microenvironment (27). There is a dramatic increase in platelet activation markers, such as P-selectin, an adherent molecule, and angiogenesis markers in the platelets of cancer patients. For example, platelet lysate from breast cancer patients contains significantly higher levels of VEGF, ANGPT-1, and P-selectin, as compared to normal controls (28). In addition, intra-platelet levels of VEGF and PDGF are increased in colorectal cancer patients compared to those of healthy controls (28). Notably, these angiogenic regulators are detected in the early phase, and their levels are associated with clinical parameters (28-30). As has already been mentioned, VEGF plays the most important role in this process. This is supported in relevant studies, such as a metaanalysis by Kut et al., which demonstrated that, in cancer patients, the concentration of VEGF was $413000 \mathrm{pg} / \mathrm{ml}$, as compared to only $216000 \mathrm{pg} / \mathrm{ml}$ in healthy controls (31). It has also been found that this pro-angiogenic factor may function as a diagnostic and prognostic biomarker, since it appears to predict cancer progression (32). Notably, although PDGF has also been associated with tumor growth and angiogenesis in many studies, it has not been attributed a specific role in cancer progression (33).

Additionally, platelets have been shown to recruit endothelial progenitor cells (EPCs) from bone marrow and increase their angiogenic potential. EPCs are also involved in neoangiogenesis (34). This has been demonstrated in B16-F10 tumors implanted in mice, an effect that has been attributed primarily to the platelet stromal-derived factor-1 (SDF-1) $(35,36)$, and secondarily to other factors, such as VEGF and ANGPT-1, which are also secreted by the activated platelets as described before $(37,38)$. Moreover, it seems that platelets contribute to the differentiation and maturation of EPCs that will eventually become the endothelial cells that line the novel blood vessels of the early metastatic niche (34).

Finally, platelets seem to have a role in the formation of the lymphatic network of the tumor as well, since agranules contain VEGF-C, the most important regulator of lymphangiogenesis (39). Furthermore, a connection has been found between podoplanin, expressed in various cancer types, and TCIPA (40). Although it has not yet been confirmed that platelets do indeed guide the creation of lymphatic vessels in the tumor microenvironment, there is at least one study in esophageal cancer that has demonstrated an association between platelet counts, both in the circulation and in the tumor microenvironment, and lymphangiogenesis (41). 


\section{Impairing the Host Defense Mechanisms}

As previously mentioned, platelets protect CTCs from NKmediated lysis during their voyage through the circulation. Although that may appear as a mostly mechanical process, it has been shown that platelets need to undergo activation in order to shield tumor cells from lysis (42). Platelet activation leads to the expression of the glucocorticoid-induced TNF-related ligand (GITRL), a member of the TNF receptor superfamily, on their surface membrane. GITRL binds to its receptor on the NK cell membrane and inhibits the cytotoxic properties of the latter, by impairing its lytic activity and the secretion of IFN- $\gamma$ (43). It has been shown that the protective role of platelets toward tumor cells is not limited in the context of CTCs, but it is a phenomenon observed in the tumor microenvironment as well. It has been demonstrated that the releasate from activated platelets contains a multitude of soluble factors that exert an inhibitory effect on NK cells. For example, TGF- $\beta$ secreted during TCIPA has been found to downregulate natural killer group 2D (NKG2D) immunoreceptor, impairing lytic activity and IFN- $\gamma$ secretion (44). Also, it has been hypothesized that the transfer of platelet-derived MHC-I onto the surface of the tumor cells during aggregation, may further limit the NK-mediated attack of the immune system to the developing metastatic niche (45).

Platelets also interact with other immune cells, apart from NK, like macrophages and T-cells, and their effects on them may contribute in the creation of an immunosuppressive microenvironment. For example, the micrometastatic niche is rich in platelet-derived and tumor cell-derived TGF- $\beta$, which is suppressive for both CD4+ and CD8+ T-cell functions as well (46). Also, there is evidence that platelets represent the main source of functional TGF- $\beta$, both systemically and in the tumor microenvironment, through the expression of TGF- $\beta$ docking receptor Glycoprotein A Repetitions Predominant (GARP). Thus, platelets constrain T-cell immunity through a GARP-TGF$\beta$ axis (47). Conclusively, platelets seem to have a substantial contribution in the induction of a localized state of dormancy in the host defense mechanisms, a situation that is vital for the development of the early metastatic foci.

Moreover, platelets have been implicated in the activation of neutrophils and the creation of neutrophil extracellular traps (NETs), in a process called NETosis (48). The interaction between platelets and neutrophils is bidirectional since, on one hand, platelet TLR4 triggers NETosis, and on the other, extracellular DNA from NETs triggers platelet activation (49). Also, this extracellular DNA contributes to cancer-associated thrombosis, which confers a dismal prognosis and represents the secondleading cause of death in cancer patients (47).

\section{PRECLINICAL EVIDENCE AND EXPERIMENTAL MODELS}

There exists enough evidence from preclinical studies and experimental models to support the pivotal role of platelets in the creation of the early metastatic niche $(50,51)$. Gasic et al. were the first to offer experimental evidence for the role of platelets in cancer. More specifically, in an experimental mouse model, it was demonstrated that the number of metastases in mice can be decreased by reducing the number of host platelets before tumor inoculation, and that this effect is independent of the method used to decrease the platelets (neuraminidase or anti-platelet serum) (52). This finding has been reproduced in other studies as well (53).

On the contrary, when injecting thrombocytopenic mice with human-derived platelets, the rate and extent of metastatic spread increased substantially (54). These experiments provide hints for the existence of a potential correlation between the absolute platelet count and cancer progression that can even be analyzed quantitatively.

Furthermore, Kerr et al., also workingon mouse models, demonstrated that platelets facilitate communication between pre-metastatic tumor cells and their pre-metastatic niche in bone tissue (10). Also, Labelle et al. showed that platelets induce the recruitment of granulocytes through the secretion of CXCL5 and CXCL7, promoting the creation of early metastatic sites (4). Finally, blocking of platelet-CTC interaction has also been evaluated as a method to reduce metastasis. Recently, Gareau et al. demonstrated that blocking this interaction using the $\mathrm{P} 2 \mathrm{Y} 12$ inhibitor ticagrelor, reduced the number of metastasis and prolonged survival in a murine breast cancer model (55).

\section{POTENTIAL CLINICAL RELEVANCE AND FUTURE PERSPECTIVES}

Thrombocytosis of malignancy constitutes a well-known paraneoplastic syndrome, which is promoted by a multitude of cancer-related cytokines and growth factors, such as G-CSF, GMCSF, IL-1, IL-6 and, more importantly, TPO (56-58). TPO is the main cytokine responsible for the stimulation of megakaryocyte production and platelet development, and has been found to be elevated in certain tumor types, such as in ovarian cancer $(59,60)$. Thrombocytosis in cancer patients is a common finding, and it is correlated with adverse prognosis. Several studies have reported that cancer incidence increases with increasing platelet count, and for those with an absolute platelet number more than $3.5 \times 10^{11} / \mathrm{L}$, the risk has been estimated to reach $3 \%$ in 1 year of observation $(61,62)$.

Based on the experimental data, targeting platelets appears a promising approach against cancer itself. Most of the clinical trials have evaluated aspirin, perhaps the most well-studied antiplatelet drug, as an anticancer agent. In a 2012 meta-analysis of 5 randomized clinical trials (RCT), aspirin has been found to reduce the risk of metastasis and the risk of death by cancer in patients with adenocarcinoma, irrespective of the organ of origin (63). In another meta-analysis of 15 RCTs, that included a substantial number of participants, daily aspirin was also found to reduce cancer deaths (63). However, other RCTs have found no such correlation $(64,65)$. Several clinical trials evaluating the effect of aspirin on cancer are currently ongoing ${ }^{1,2,3}$. One such large trial, the ADD-ASPIRIN Trial, is currently recruiting

\footnotetext{
${ }^{1}$ Aspirin for Dukes C and HighRisk Dukes B Colorectal Cancers (ASCOLT). ClinicalTrials.gov Identifier: NCT00565708.

${ }^{2}$ Finding the Best Dose of Aspirin to Prevent Lynch Syndrome Cancers (CaPP3 Israel). ClinicalTrials.gov Identifier: NCT02497820.

${ }^{3}$ ADD-ASPIRIN Trial website. http://www.addaspirintrial.org
} 
patients who previously had treatment for early cancer of the breast, stomach, esophagus, prostate and colon ${ }^{3}$. The aim is to test whether 5 years of aspirin prophylaxis post initial treatment for cancer, can prevent or delay cancer recurrence. The hypothesis that aspirin exerts its anticancer actions by inhibiting the formation of the pre-metastatic niche has recently been tested in a murine experimental model for lung metastasis. It has been found that thromboxane A2 (TXA2) was the prostanoid product of COX-1 responsible for this anti-metastatic effect. Inhibition of the COX-1/TXA2 pathway in platelets decreased their aggregation on tumor cells, limited endothelial activation and the adhesion of tumor cells to the endothelium, and impaired the recruitment of metastasis-promoting monocytes/macrophages, thus diminishing the formation of pre-metastatic niche (66).

Previous studies had shown that other platelet activation pathways could contribute to the establishment of the intravascular metastatic niche. In particular, Clopidogrel a $\mathrm{P} 2 \mathrm{Y} 12$ receptor antagonist, and eptifibatide an $\alpha \operatorname{IIb} \beta 3$ integrin inhibitor, two drugs used in the clinical practice to reduce platelet aggregation, were found to be associated with reduction in experimental metastasis $(14,67)$. This finding was not confirmed in the recent study by Lucotti et al. (66). However, further studies are required to explore the role of all possible platelet activation pathways at different stages of metastatic progression including the stages of epithelial-mesenchymal transition and extravasation $(14,68)$. This approach will potentially lead to the identification of new therapeutic targets and consequently antiplatelet agents to be used against the micrometastatic niche formation.

Finally, the creation of modified platelets that retained platelet binding functions but were incapable of functional activation and aggregation, termed "platelet decoys," led to encouraging results in mouse models, where simultaneous injection of the platelet

\section{REFERENCES}

1. Palacios-Acedo AL, Mège D, Crescence L, Dignat-George F, Dubois C, Panicot-Dubois L. Platelets, thrombo-inflammation, and cancer: collaborating with the enemy. Front Immunol. (2019) 10:1805. doi: 10.3389/fimmu.2019.01805

2. Mezouar S, Frère C, Darbousset R, Mege D, Crescence L, DignatGeorge F, et al. Role of platelets in cancer and cancer-associated thrombosis: experimental and clinical evidences. Thromb Res. (2016) 139:6576. doi: 10.1016/j.thromres.2016.01.006

3. Lambert AW, Pattabiraman DR, Weinberg RA. Emerging biological principles of metastasis. Cell. (2017) 168:67091. doi: 10.1016/j.cell.2016.11.037

4. Labelle M, Begum S, Hynes RO. Platelets guide the formation of early metastatic niches. Proc Natl Acad Sci USA. (2014) 111:E305361. doi: 10.1073/pnas.1411082111

5. Bendas G, Borsig L. Cancer cell adhesion and metastasis: selectins, integrins, and the inhibitory potential of heparins. Int J Cell Biol. (2012) 2012:676731. doi: 10.1155/2012/676731

6. Nieswandt B, Hafner M, Echtenacher B, Männel DN. Lysis of tumor cells by natural killer cells in mice is impeded by platelets. Cancer Res. (1999) 59:1295300.

7. Labelle M, Begum S, Hynes RO. Direct signaling between platelets and cancer cells induces an epithelial-mesenchymal-like transition and decoys with tumor cells inhibited metastatic tumor growth (69). The production of reversible drug-free antiplatelet agents by modifying human platelets, is of particular clinical importance as it carries the potential of stopping the formation of metastasis and the burden this is associated with in patients with cancer.

\section{CONCLUSION}

Although the role of platelets in cancer progression is not limited to the preparation and maintenance of the metastatic microenvironment, this specific function is of utmost importance since the few early clusters of metastasizing tumor cells are extremely vulnerable and subject to many dangers in their surrounding environment. Accumulated data from preclinical studies and experimental models support the hypothesis that platelets contribute in every stage of the formation of the pre-metastatic niche. It is also possible that antiplatelet drugs, especially aspirin, exhibit at least part of their anticancer properties by impairing the formation of a suitable microenvironment for the development of metastases.

Whilst ongoing preclinical work is expected to shed light on additional platelet activation pathways at different stages of metastatic progression, several clinical trials aiming to evaluate antiplatelet agents in the treatment and prevention of cancer progression are currently ongoing.

\section{AUTHOR CONTRIBUTIONS}

SG and AC developed the idea and drafted the manuscript. SG created the figure. RJ critically reviewed the manuscript and contributed new ideas. The final manuscript was edited by AC and approved by all authors.

promotes metastasis. Cancer Cell. (2011) 20:576-90. doi: 10.1016/j.ccr.2011. 09.009

8. Paoli P, Giannoni E, Chiarugi P. Anoikis molecular pathways and its role in cancer progression. BiochimBiophys Acta. (2013) 1833:348198. doi: 10.1016/j.bbamcr.2013.06.026

9. Yan M, Jurasz P. The role of platelets in the tumor microenvironment: from solid tumors to leukemia. BiochimBiophys Acta. (2016) 1863:392400. doi: 10.1016/j.bbamcr.2015.07.008

10. Kerr BA, McCabe NP, Feng W, Byzova TV. Platelets govern premetastatic tumor communication to bone. Oncogene. (2013) 32:431924. doi: 10.1038/onc.2012.447

11. Boucharaba A, Serre CM, Grès S, Saulnier-Blache JS, Bordet JC, Guglielmi J, et al. Platelet-derived lysophosphatidic acid supports the progression of osteolytic bonemetastases in breast cancer. J. Clin. Investig. (2004) 114:171425. doi: 10.1172/JCI200422123

12. Leblanc R, Lee SC, David M, Bordet JC, Norman DD, Patil R, et al. Interaction of platelet-derived autotaxin with tumor integrin $\alpha \mathrm{V} \beta 3$ controls metastasis of breast cancer cells to bone. Blood. (2014) 124:314150. doi: 10.1182/blood-2014-04-568683

13. Descot A, Oskarsson T. The molecular composition of the metastatic niche. Exp Cell Res. (2013) 319:1679-86. doi: 10.1016/j.yexcr.2013.04.017

14. Wang Y, Sun Y, Li D, Zhang L, Wang K, Zuo Y, et al. Platelet P2Y12 is involved in murine pulmonary metastasis. PLoS ONE. (2013) 8:e80780. doi: 10.1371/journal.pone.0080780 
15. Sharma S, Sharma MC, Sarkar C. Morphology of angiogenesis in human cancer: a conceptual overview, histoprognostic perspective and significance of neoangiogenesis. Histopathology. (2005) 46:481-9. doi: 10.1111/j.1365-2559.2005.02142.x

16. Nishida N, Yano H, Nishida T, Kamura T, Kojiro M. Angiogenesis in cancer. Vasc. Health Risk Manag. (2006) 2:213-9. doi: 10.2147/vhrm.2006.2.3.213

17. Folkman J. Tumor angiogenesis: therapeutic implications. $N$ Engl J Med. (1971) 285:1182-6. doi: 10.1056/NEJM197111182852108

18. Folkman J. Angiogenesis in cancer, vascular, rheumatoid and other diseases. Nat Med. (1995) 1:27-31. doi: 10.1038/nm0195-27

19. Verheul HM, Hoekman K, Luykx-de Bakker S, Eekman CA, Folman CC, Broxterman HJ, et al. Platelet transporter of vascular endothelial growth factor. Clin Cancer Res. (1997) 3:2187-90.

20. Wojtukiewicz MZ, Sierko E, Hempel D, Tucker SC, Honn KV. Platelets and cancer angiogenesis nexus. Cancer Metastasis Rev. (2017) 36:24962. doi: 10.1007/s10555-017-9673-1

21. Jurasz P, Alonso-Escolano D, Radomski MW. Platelet-cancer interactions: mechanisms and pharmacology of tumour cell-induced platelet aggregation. Br J. Pharmacol. (2004) 143:819-26. doi: 10.1038/sj.bjp.07 06013

22. Pipili-Synetos E, Papadimitriou E, Maragoudakis ME. Evidence that platelets promote tube formation by endothelial cells on Matrigel. Br J Pharmacol. (1998) 125:1252-7. doi: 10.1038/sj.bjp.0702191

23. Brill A, Dashevsky O, Rivo J, Gozal Y, Varon D. Platelet-derived microparticles induce angiogenesis and stimulate post-ischemic revascularization. Cardiovasc Res. (2005) 67:30-8. doi: 10.1016/j.cardiores.2005.04.007

24. Wartiovaara U, Salven P, Mikkola H, Lassila R, Kaukonen J, Joukov $\mathrm{V}$, et al. Peripheral blood platelets express VEGF-C and VEGF which are released during platelet activation. ThrombHaemost. (1998) 80:1715. doi: 10.1055/s-0037-1615158

25. Verheul HM, Hoekman K, Lupu F, Broxterman HJ, van der Valk P, Kakkar $\mathrm{AK}$, et al. Platelet and coagulation activation with vascular endothelial growth factor generation in soft tissue sarcomas. Clin Cancer Res. (2000) 6:166-71.

26. Möhle R, Green D, Moore MA, Nachman RL, Rafii S. Constitutive production of thrombin-induced release of vascular endothelial growth factor by human megakaryocytes and platelets. Proc Natl Acad Sci USA. (1997) 94:6638. doi: 10.1073/pnas.94.2.663

27. Kuznetsov HS, Marsh T, Markens BA, Castaño Z, Greene-Colozzi A, Hay SA, et al. Identification of luminal breast cancers that establish a tumor-supportive macroenvironment defined by proangiogenic platelets and bone marrow-derived cells. Cancer Discov. (2012) 2:1150-65. doi: 10.1158/2159-8290.CD-12-0216

28. Caine GJ, Lip GY, Blann AD. Platelet-derived VEGF, Flt-1, angiopoietin1 and P-selectin in breast and prostate cancer: further evidence for a role of platelets in tumour angiogenesis. Ann Med. (2004) 36:2737. doi: 10.1080/07853890410026098

29. Chater C, Bauters A, Beugnet C, M'Ba L, Rogosnitzky M, Zerbib P. Intraplatelet Vascular endothelial growth factor and platelet-derived growth factor: new biomarkers in carcinoembryonic antigen-negative Colorectal Cancer? Gastrointest Tumors. (2018) 5:32-7. doi: 10.1159/000486894

30. Han H, Cao FL, Wang BZ, Mu XR, Li GY, Wang XW. Expression of angiogenesis regulatory proteins and epithelial-mesenchymal transition factors in platelets of the breast cancer patients. Sci World J. (2014) 2014:878209. doi: 10.1155/2014/878209

31. Kut C, Mac Gabhann F, Popel AS. Where is VEGF in the body? A meta-analysis of VEGF distribution in cancer. Br J Cancer. (2007) 97:97885. doi: 10.1038/sj.bjc.6603923

32. Jelkmann W. Pitfalls in the measurement of circulating vascular endothelial growth factor. Clin Chem. (2001) 47:617-23. doi: 10.1093/clinchem/47.4.617

33. Buergy D, Wenz F, Groden C, Brockmann MA. Tumor-platelet interaction in solid tumors. Int J Cancer. (2012) 130:2747-60. doi: 10.1002/ijc.27441

34. Langer H, May AE, Daub K, Heinzmann U, Lang P, Schumm M, et al. Adherent platelets recruit and induce differentiation of murine embryonic endothelial progenitor cells to mature endothelial cells in vitro. Circ Res. (2006) 98:e2-10. doi: 10.1161/01.RES.0000201285.87524.9e

35. Stellos $\mathrm{K}$, Langer $\mathrm{H}$, Daub $\mathrm{K}$, Schoenberger $\mathrm{T}$, Gauss A, Geisler T, et al. Platelet-derived stromal cell-derived factor1 regulates adhesion and promotes differentiation of human
CD34+ cells to endothelial progenitor cells. Circulation.

(2008) 117:206-15. doi: 10.1161/CIRCULATIONAHA.107.714691

36. Jin DK, Shido K, Kopp HG, Petit I, Shmelkov SV, Young LM, et al. Cytokine-mediated deployment of SDF-1 induces revascularization through recruitment of CXCR4+ hemangiocytes. Nat Med. (2006) 12:557-67. doi: 10.1038/nm1400

37. Feng W, Madajka M, Kerr BA, Mahabeleshwar GH, Whiteheart SW, Byzova TV. A novel role for platelet secretion in angiogenesis: mediating bone marrow-derived cell mobilization and homing. Blood. (2011) 117:3893902. doi: 10.1182/blood-2010-08-304808

38. Matsui Y, Amano H, Ito Y, Eshima K, Suzuki T, Ogawa F, et al. Thromboxane $\mathrm{A}_{2}$ receptor signaling facilitates tumor colonization through P-selectinmediated interaction of tumor cells with platelets and endothelial cells. Cancer Sci. (2012) 103:700-7. doi: 10.1111/j.1349-7006.2012.02200.x

39. Bertozzi CC, Hess PR, Kahn ML. Platelets: covert regulators of lymphatic development. ArteriosclerThrombVasc Biol. (2010) 30:2368-71. doi: 10.1161/ATVBAHA.110.217281

40. Suzuki-Inoue K, Kato Y, Inoue O, Kaneko MK, Mishima K, Yatomi Y, et al. Involvement of the snake toxin receptor CLEC-2, in podoplaninmediated platelet activation, by cancer cells. J Biol Chem. (2007) 282:259936001. doi: 10.1074/jbc.M702327200

41. Schoppmann SF, Alidzanovic L, Schultheis A, Perkmann T, Brostjan C, Birner P. Thrombocytes correlate with lymphangiogenesis in human esophageal cancer and mediate growth of lymphatic endothelial cells in vitro. PLoS ONE. (2013) 8:e66941. doi: 10.1371/journal.pone.0066941

42. Palumbo JS, Talmage KE, Massari JV, La Jeunesse CM, Flick MJ, Kombrinck KW, et al. Platelets and fibrin(ogen) increase metastatic potential by impeding natural killer cell-mediated elimination of tumor cells. Blood. (2005) 105:17885. doi: 10.1182/blood-2004-06-2272

43. Placke T, Salih HR, Kopp HG. GITR ligand provided by thrombopoietic cells inhibits NK cell antitumor activity. J Immunol. (2012) 189:15460. doi: 10.4049/jimmunol.1103194

44. Kopp HG, Placke T, Salih HR. Platelet-derived transforming growth factor-beta down-regulates NKG2D thereby inhibiting natural killer cell antitumor reactivity. Cancer Res. (2009) 69:7775-83. doi: 10.1158/0008-5472.CAN-09-2123

45. Placke T, Örgel M, Schaller M, Jung G, Rammensee HG, Kopp HG, Salih HR. Platelet-derived MHC class I confers a pseudonormal phenotype to cancer cells that subverts the antitumor reactivity of natural killer immune cells. Cancer Res. (2012) 72:440-8. doi: 10.1158/0008-5472.CAN-11-1872

46. Kimball AS, Obi AT, Diaz JA, Henke PK. The Emerging Role of NETs in Venous Thrombosis and Immunothrombosis. Front Immunol. (2016) 7:236. doi: 10.3389/fimmu.2016.00236

47. Rachidi S, Metelli A, Riesenberg B, Wu BX, Nelson MH, Wallace C, et al. Platelets subvert T cell immunity against cancer via GARP-TGF $\beta$ axis. $S c i$ Immunol. (2017) 2:eaai7911. doi: 10.1126/sciimmunol.aai7911

48. Jorch SK, Kubes P. An emerging role for neutrophil extracellular traps in noninfectious disease. Nat Med. (2017). 23:279-87. doi: 10.1038/nm.4294

49. Demers M, Krause DS, Schatzberg D, Martinod K, Voorhees JR, Fuchs TA, et al. Cancers predispose neutrophils to release extracellular DNA traps that contribute to cancer-associated thrombosis. Proc Natl Acad Sci USA. (2012) 109:13076-81. doi: 10.1073/pnas.1200419109

50. Tang DG, Honn KV. Adhesion molecules and tumor metastasis: an update. Invasion Metastasis. (1994-1995) 14:109-22.

51. Honn KV, Tang DG, Chen YQ. Platelets and cancer metastasis: more than an epiphenomenon. SeminThrombHemost. (1992) 18:392-415. doi: 10.1055/s-2007-1002578

52. Gasic GJ, Gasic TB, Stewart CC. Antimetastatic effects associated with platelet reduction. Proc Natl Acad Sci USA. (1968) 61:46-52. doi: 10.1073/pnas.61.1.46

53. Karpatkin S, Pearlstein E, Salk PL, Yogeeswaran G. Role of platelets in tumor cell metastases. Ann N Y Acad Sci. (1981) 370:101-18. doi: 10.1111/j.1749-6632.1981.tb29726.x

54. Nierodzik ML, Klepfish A, Karpatkin S. Role of platelets, thrombin, integrin IIb-IIIa, fibronectin and von Willebrand factor on tumor adhesion in vitro and metastasis in vivo. ThrombHaemost. (1995) 74:282-90. doi: 10.1055/s-0038-1642691

55. Gareau AJ, Brien C, Gebremeskel S, Liwski RS, Johnston B, Bezuhly M. Ticagrelor inhibits platelet-tumor cell interactions and metastasis in 
human and murine breast cancer. Clin Exp Metastasis. (2018) 35:2535. doi: 10.1007/s10585-018-9874-1

56. Kato N, Yasukawa K, Onozuka T, Kimura K. Paraneoplastic syndromes of leukocytosis, thrombocytosis, and hypercalcemia associated with squamous cell carcinoma. J Dermatol. (1999) 26:352-8. doi: 10.1111/j.1346-8138.1999.tb03487.x

57. Estrov Z, Talpaz M, Mavligit G, Pazdur R, Harris D, Greenberg $\mathrm{SM}$, et al. Elevated plasma thrombopoietic activity in patients with metastatic cancer-related thrombocytosis. Am J Med. (1995) 98:5518. doi: 10.1016/S0002-9343(99)80013-8

58. Gastl G, Plante M, Finstad CL, Wong GY, Federici MG, Bander NH, et al. High IL-6 levels in ascitic fluid correlate with reactive thrombocytosis in patients with epithelial ovarian cancer. Br J Haematol. (1993) 83:43341. doi: 10.1111/j.1365-2141.1993.tb04668.x

59. Stone RL, Nick AM, McNeish IA, Balkwill F, Han HD, Bottsford-Miller J, et al. Paraneoplastic thrombocytosis in ovarian cancer. N Engl J Med. (2012) 366:610-8. doi: 10.1056/NEJMoa1110352

60. Sasaki Y, Takahashi T, Miyazaki H, Matsumoto A, Kato T, Nakamura K, et al. Production of thrombopoietin by human carcinomas and its novel isoforms. Blood. (1999) 94:1952-60. doi: 10.1182/blood.V94.6.1952.418k18_1952_1960

61. Ankus E, Price SJ, Ukoumunne OC, Hamilton W, Bailey SER. Cancer incidence in patients with a high normal platelet count: a cohort study using primary care data. Fam Pract. (2018) 35:671-5. doi: 10.1093/fampra/cmy018

62. Bailey SER, Ukoumunne OC, Shephard EA, Hamilton W. Clinical relevance of thrombocytosis in primary care: a prospective cohort study of cancer incidence using English electronic medical records and cancer registry data. Br J Gen Pract. (2017) 67:e405-13. doi: 10.3399/bjgp17X691109

63. Algra AM, Rothwell PM. Effects of regular aspirin on long-term cancer incidence and metastasis: a systematic comparison of evidence from observational studies versus randomised trials. Lancet Oncol. (2012) 13:51827. doi: 10.1016/S1470-2045(12)70112-2

64. Stürmer T, Glynn RJ, Lee IM, Manson JE, Buring JE, Hennekens $\mathrm{CH}$. Aspirin use and colorectal cancer: post-trial follow-up data from the Physicians' Health Study. Ann Intern Med. (1998) 128:713-20. doi: 10.7326/0003-4819-128-9-199805010-00003

65. Cook NR, Lee IM, Gaziano JM, Gordon D, Ridker PM, Manson JE, et al. Low-dose aspirin in the primary prevention of cancer: the Women's Health Study: a randomized controlled trial. JAMA. (2005) 294:4755. doi: 10.1001/jama.294.1.47

66. Lucotti S, Cerutti C, Soyer M, Gil-Bernabé AM, Gomes AL, Allen PD, et al Aspirin blocks formation of metastatic intravascular niches by inhibiting platelet-derived COX-1/thromboxane A2. J Clin Invest. (2019) 129:184562. doi: 10.1172/JCI121985

67. Gebremeskel S, LeVatte T, Liwski RS, Johnston B, Bezuhly M. The reversible P2Y12 inhibitor ticagrelor inhibits metastasis and improves survival in mouse models of cancer. Int J Cancer. (2015) 136:234-40. doi: 10.1002/ijc.28947

68. Ward Y, Lake R, Faraji F, Sperger J, Martin P, Gilliard C, et al. Platelets promote metastasis via binding tumor CD97 leading to bidirectional signaling that coordinates transendothelial migration. Cell Rep. (2018) 23:808-22. doi: 10.1016/j.celrep.2018.03.092

69. Papa AL, Jiang A, Korin N, Chen MB, Langan ET, Waterhouse $A$, et al. Platelet decoys inhibit thrombosis and prevent metastatic tumor formation in preclinical models. Sci Transl Med. (2019) 11:eaau5898. doi: 10.1126/scitranslmed.aau5898

Conflict of Interest: The authors declare that the research was conducted in the absence of any commercial or financial relationships that could be construed as a potential conflict of interest.

Copyright (C) 2020 Gkolfinopoulos, Jones and Constantinidou. This is an open-access article distributed under the terms of the Creative Commons Attribution License (CC $B Y)$. The use, distribution or reproduction in other forums is permitted, provided the original author(s) and the copyright owner(s) are credited and that the original publication in this journal is cited, in accordance with accepted academic practice. No use, distribution or reproduction is permitted which does not comply with these terms. 